\title{
LA PALABRA DEFORMADA: CONVERSACIONES CON EL POEMA “EN ESTA NOCHE, EN ESTE MUNDO” DE ALEJANDRA PIZARNIK
}

\author{
THE DISTORTED WORD: CONVERSATIONS WITH THE POEM “TONIGHT, IN \\ THIS WORLD" BY ALEJANDRA PIZARNIK
}

Liliana Moreno M.

Universidad Nacional de Colombia

\section{Resumen:}

Este artículo pretende analizar el poema "En esta noche, en este mundo" de la poeta argentina Alejandra Pizarnik, centrándonos en la idea del "silencio", el eje fundamental del poema. Para profundizar en este análisis se ha recurrido a distintas teorías del lenguaje con el fin de conocer qué se esconde tras sus versos y tras la idea de silencio que nos transmite.

\section{Palabras claves:}

Alejandra Pizarnik, poema, silencio, lenguaje.

\section{Abstract:}

This article aims to analyse the poem "Tonight, in this world" by the Argentinean poet Alejandra Pizarnik, focusing on the idea of "silence", central idea of the poem. In order to go deep into the analysis we have used different linguistic theories with the purpose of knowing what is behind the verses and the idea of silence which is transmitted.

\section{KEY WORD:}

Alejandra Pizarnik, poem, silence, language. 
La palabra dice lo que dice

y además más

y otra cosa"

(Alejandra Pizarnik)

Quizá, como afirma Harold Bloom, la respuesta a un poema sólo puede ser otro poema. Sin embargo, quedan aquí los vestigios de mi reunión con un poema que ha sido mi sombra desde hace ya varios años. Busqué durante mucho tiempo esta oportunidad o mejor, esta exigencia: expresar una lectura intentando abandonar las frases rituales que nos posicionan como seres capaces de objetividad (como si ésta constituyera un logro... evidentemente, podrían condecorarnos con la verdad).

Me propongo esencialmente, señalar cómo se construye el sentido en el poema, y cómo se produce una coherencia entre lo distintos niveles discursivos. El poema que presento a continuación es el objeto de análisis principal, sin embargo, su lectura implica, además de muchos otros componentes, el conocimiento de la obra total de Alejandra Pizarnik, puesto que en este caso, reconocer el co-texto permite distinguir los elementos particulares de la poética que multiplican el sentido de la obra que presento a continuación:
EN ESTA NOCHE, EN ESTE MUNDO
A Martha Isabel Moia
en esta noche en este mundo
las palabras del sueño de la infancia de la muerte
nunca es eso lo que uno quiere decir
la lengua natal castra
a lengua es un órgano de conocimiento
del fracaso de todo poema
castrado por su propia lengua
que es el órgano de la re-creación
del re-conocimiento
pero no el de la resurrección
de algo a modo de negación
de mi horizonte de maldoror con su perro
$y$ nada es promes
entre lo decible
que equivale a mentir
(todo lo que se puede decir es mentira)
el resto es silencio
sólo que el silencio no existe
las palabras
no hacen el amor
hacen la ausencia
si digo agua ¿beberé?
si digo pan ¿comeré?
en esta noche en este mundo
extraordinario silencio el de esta noche
lo que pasa con el alma es que no se ve
o que pasa con la mente es que no se ve

lo que pasa con el espiritu es que no se ve

¿de dónde viene esta conspiración de

invisibilidades?

ninguna palabra es visible

sombras

recintos viscosos donde se oculta

la piedra de la locura

corredores negros

los he recorrido todos

¡oh quédate un poco más entre nosotros!

mi persona está herida

mi primera persona del singular

escribo como quien con un cuchillo alzado en la

oscuridad

escribo como estoy diciendo

la sinceridad absoluta continuaría siendo

lo imposible

¡oh quédate un poco más entre nosotros!

los deterioros de las palabras

deshabitando el palacio del lenguaje

el conocimiento entre las piernas

¿qué hiciste del don del sexo?

oh mis muertos

me los comi me atragante

no puedo más de no poder más

palabras embozadas

todo se desliza

hacia la negra licuefacción

y el perro de maldoror

en esta noche en este mundo

donde todo es posible

salvo

el poema

hablo

sabiendo que no se trata de eso

siempre no se trata de eso

oh ayúdame a escribir el poema más prescindible

el que no sirva ni para

ser inservible

ayúdame a escribir palabras

en esta noche en

Publicado en Árbol de Fuego, Caracas, 45, diciembre de 1971

El reconocimiento de los rasgos generales de la poética de Alejandra Pizarnik, a través de este poema, permite también el acceso a la lectura del silencio estético, entendiendo éste como la omisión total de significantes, tal como lo expresé en el trabajo anterior. De manera que en el presente escrito, intento también un análisis a ese tipo de silencio que funciona como oposición a la obra total de la poeta argentina.

Iniciar este recorrido implica partir de una idea acerca del lenguaje, que se opone a la concepción ingenua de la palabra como manifestación directa y diáfana del 
pensamiento. La sospecha respecto a la manera como opera el lenguaje, así como el reconocimiento de la escisión entre lo que se dice, lo que se piensa y lo que se hace, son características de un pensamiento que entra en ruptura con una tradición positiva que veía en el estudio de las formas textuales, la posibilidad de una lectura científica que aproximara al lector a la verdad de texto.

La postura nietzscheana, por ejemplo, se sostiene en el origen metafórico del lenguaje, enfatizando en la imposibilidad de construir la verdad en tanto correspondencia entre la palabra y lo que nombra. Se habla pues, de una inconsciencia en el uso del lenguaje como mundo construido y separado del mundo real, que provoca en el uso del lenguaje un acomodamiento a éste y un engaño.

Así, la imposibilidad de DECIR, apartándose de un pensamiento impuesto, implica también un ataque a las formas que atrapan al individuo en una realidad creada por la cultura y estancan la producción del conocimiento, anulando de paso al individuo. Alejandra Pizarnik, como otros artistas, deforma la palabra que se ha convertido en herramienta de engaño, prisión y tumba, mediante el discurso estético, que posibilita la creación de un mundo paralelo, operación metafórica en la cual se alude a la experiencia del ser en y con el mundo. El discurso estético se muestra abiertamente como juego que busca la honestidad y reconoce la imposibilidad de manifestar una verdad.

Por tanto, en un primer encuentro con el poema, además de encontrar la inscripción de dicho texto dentro del discurso estético que expresa la autenticidad en mayor grado, en relación con los otros tipos de discurso, se halla también el reconocimiento de una forma literaria particular, de un género: la lírica. Dentro del discurso literario, ésta es la forma en la cual se expresa un mayor grado de subjetividad, pues el poeta libera su voz o sus voces en el verso. En el proceso de producción, como ocurre en todo discurso literario, el poeta no está sujeto a la mirada del otro, no escribe específicamente para un tipo de lector, sino que expresa en la obra una subjetividad que llama al lector al diálogo, es decir, al enfrentamiento del Otro con el texto:

"Si me preguntan para quién escribo me preguntan por el destinatario de mis poemas. La pregunta garantiza, tácitamente la presencia del personaje.

De modo que somos tres: yo, el poema, el destinatario. Este triángulo en acusativo precisa un pequeño examen.

Cuando termino un poema, no lo he terminado. En verdad lo abandono y el poema ya no es mío, más exactamente el poema existe apenas.
A partir de este momento el triángulo ideal depende del destinatario o lector unicamente el lector puede terminar el poema inacabado, rescatar sus múltiples sentidos, agregarle otros nuevos. Terminar equivale aquí a dar vida nuevamente, a re-crear; cuando escribo jamás evoco un lector. Tampoco se me ocurre pensar en el destino de lo que estoy escribiendo. Nunca he buscado al lector ni antes, en durante, ni después del poema. Es por esto, cre que he tenito encuentes, ni durante, ni despues del poema. Es por esto, creo, que he tenido encuentros imprevistos con verdaderos lectía la emocion de saberme comprendida en profundidad. A lo que agrego una frase propicia de Gastón Bachelard: el poeta debe crear su lector y de ninguna manera expresar ideas comunes"1

En esta reflexión de Alejandra Pizarnik se distinguen los tres elementos, que a nivel exterior conforman el triángulo comunicativo: el poeta, el poema y el lector. Pero el texto no sólo permite un contacto entre los dos sujetos, también propicia la intersubjetividad en la relación poema - lector, en tanto el texto mismo permite recuperar la intención pues en él se ha fijado la huella de una experiencia particular con el mundo. De igua modo, el acceso al sentido del texto está signado por el saber del lector a partir de cual puede establecerse un diálogo en donde entra a jugar otra triada: Yo, tú y él, entendiendo cada una de estas como instancias discursivas internas. A partir de éstas se generan en el discurso distintas relaciones que generan los tres niveles discursivos:

- El nivel de la historia

- El nivel de la enunciación

- El nivel del discurso

El nivel de la historia se articula a través de la relación yo - él. El componente cultural es el elemento básico de este nivel, de donde se desprende el referente. Se considera aquí una estructura o texto que está ahí, sin quien la produce. De manera que el poema ha de entenderse en este nivel como una unidad con estructura lógica, a partir de la cual se abstrae un significado que responde a la pregunta: ¿qué dice el texto? ¿de que habla?

En esta noche, en este mundo, habla de la imposibilidad de DECIR, de la angustia del poeta que se enfrenta a un mundo donde la sinceridad absoluta, la expresión individual y original son imposibles. En el poema hay una voz que expresa la necesidad de escribir un poema. Y por poema se entiende, al final del texto, una expresión absolutamente auténtica, liberada de las formas y contenidos culturales que oprimen al ser. En este caso, la referencia es un proceso de significación: DECIR, expresar a través del poema. Por tanto, podríamos hablar de una referencia metalingüística que tiene como base un saber: la escisión entre la representación y lo representado.

1 Alejandra Pizarnik, El poema y su lector, en "Alejandra Pizarnik: Obras escogidas" Ediciones Hölderlin, Medellín, 1996, p. 214

Culturas y Literaturas, octubre 2006 
Se entiende el lenguaje, en el poema, como una envoltura que impide el crecimiento del ser, pues este último está condicionado por las formas y contenidos que implican siempre un modo se ser que es reproducción, copia, clon fabricado por una organización. Por esta razón, quien habla en el poema expresa la necesidad de hallar una expresión libre que le permita reconocerse, así, como trasfondo el texto contiene las preguntas ¿quién soy? ¿Quién habla aquí? Que jamás se resuelven. Tal angustia se relaciona, no sólo con una experiencia límite a través de la palabra en el discurso estético (que pese a ser el que posee mayor autenticidad, no logra alcanzarla), sino también, con voces anteriores: Nietszche, Blanchot, Artaud, Bachelard... estos dos últimos, citados en otras obras por la poeta.

Lo anterior señala ya una tradición que respalda el horror expresado en el poema ante la visión de la palabra como la posibilidad de desbordamiento del ser a través de la deformación de la misma y la vez como aquello que precisamente actúa como máscara en tanto se supone en la lengua un contenido cultural que se expresa más enfáticamente en las convenciones lingüísticas de las cuales es imposible escapar. Nietszche por ejemplo, se pregunta: ¿es el lenguaje la expresión adecuada de todas las realidades? ${ }^{2}$

En el poema al cual me refiero sólo se ve una salida: el silencio. Aunque se dice en un momento que no existe, se invoca, se anhela, se convierte paulatinamente en dios al que se ruega otorgue palabras verdaderas, palabras capaces de nombrar, palabras que sean un verbo encarnado, palabras como emanaciones auténticas del ser que se distingan de las palabras - instrumento, de las que sirven.

Si como también apuntó Bajtín, el hombre es una multiplicidad de voces, es decir es producto de todas sus máscaras, ¿existe un rostro? ¿Cómo nombrarlo, si no en el silencio? Hablamos, pues, de una necesidad humana que surge de la experiencia estética, llega a fundirse con la ética, en el sentido en que supera la moral y se lanza a la búsqueda de la verdad del ser fuera de los límites del lenguaje y por tanto, de la cultura. Así, lo estético, , llega a confundirse, en el silencio, con lo ético, con un deber ser que está por encima de las reglas y prohibiciones sociales (un deber ser que busca la autenticidad y una comunicación profunda, más allá del mero contacto, una posición ética soportada en la sinceridad).

Franco Rella, realiza un estudio sobre la relación silencio y palabra, analizando el fenómeno especialmente en la literatura y la filosofía. Muestra desde autores como Wittgenstein, Benjamin, Kierkegaard, Baudelaire y Kafka, una situación común, una angustia ante un lenguaje incapaz ya de decir, y a la vez un impulso por lanzarse contra los límites del lenguaje: este impulso es precisamente la dimensión informulable

2 F. Nietszche, "Sobre la verdad y la mentira en sentido extramoral" Tecnos, Madrid, 1990 de la ética ${ }^{3}(\ldots)$ La imposibilidad de nombrar el espacio de la ética debe conllevar la renuncia a todo discurso que pretenda ir más allá del mundo de lo decible(..) pero este silencio es una gran palabra. ${ }^{4}$ Se muestra así, que definitivamente el lenguaje no puede decirlo todo, que ante nuevos modos de experimentar el mundo que nacen especialmente en la experiencia estética, se requiere una liberación de las formas y los contenidos tradicionales. El sentimiento de inefabilidad surge de la experiencia de lo nuevo, y esto nuevo, es producto de un vaciamiento de las visiones de mundo a las que está sujeto el individuo. Así, la nueva mirada al mundo, provoca la angustia por decir que no logra acomodarse a las reglas del lenguaje establecido, que contiene sólo las visiones de mundo antiguas. Y dicha angustia está asociada a la muerte, pues como ella, aquello indecible queda en el no - sentido, en el absurdo, ya que lo que no tiene nombre no existe.

En el nivel de la enunciación se aprecia cómo en el texto se traza una perspectiva determinada respecto al mundo, así, el yo del poema, como entidad que organiza el discurso, está de alguna manera sujeto a la forma artística que ya mencionamos, la lírica. Es pues, un texto conformado por versos y estrofas, conforme a la tradición literaria; sin embargo corresponde a una época en la cual ya se han abandonado la métrica y la rima, pues se intenta expresar la autenticidad a través de la experimentación con la imagen y se busca una musicalidad propia. Se suprimen los signos de puntuación, otorgando a cada verso una doble relación, permitiendo así múltiples lecturas:

"en esta noche en este mundo

las palabras del sueño de la infancia de la muerte

nunca es eso lo que uno quiere decir

la lengua natal castra

la lengua es un órgano de conocimiento

del fracaso de todo poema(...)"

En primer lugar, se expresa aquí un yo responsable del discurso, pero que se convierte en personaje, pues contemplando la obra de Alejandra Pizarnik es posible descubrir varios desdoblamientos: en varios poemas ese yo se dirige a un tú que es ella misma, o bien, como en el presente poema, el yo realiza acciones que el lector sabe, no realiza quien compone el poema. Por tanto, es necesario distinguir aquí entre autor real y la voz que aparece en el poema, que podemos denominar autor ficticio.

En el primer verso el yo se ubica en un espacio tiempo: aquí y ahora. Los elementos esta noche y este mundo se irán dotando de sentido a lo largo del poema, como veremos más adelante. En el segundo verso existen varias posibilidades de interpretación, así, si el lector elige hacer pausa entre las palabras del sueño (pausa) de la infancia (pausa) de la muerte, se entenderá, por el procedimiento de elipsis, como enumeración de

3 Ética y estética son lo mismo, para el autor, fundamentado en Wittgenstein, ambas son trascendentales y por tanto, inexpresables.

4 Rella, Franco. El Silencio y Las Palabras.Paidós, Buenos Aires, 1981

Revista Internacional de Culturas y Literaturas, octubre 2006 
aquellas palabras imposibles de asociar con un referente real inefable, de acuerdo a la relación con el siguiente verso. Pero si por el contrario, las pausas no se realizan, puede interpretarse que lo que uno intenta decir mediante la imagen expresada las palabras del sueño de la infancia de la muerte, no corresponde a lo que se quiere decir, y por tanto, en el segundo verso la muerte sería el sujeto poseedor de las palabras del sueño de la infancia.

En el quinto verso: la lengua es un órgano de conocimiento hay un juego que permite que al avanzar en la lectura de la cadena significante el sentido de la palabra lengua presente variaciones, pues al definirla inicialmente como órgano implica entender este elemento en el sentido fisiológico, pero al adicionar de conocimiento, se introduce la ambigüedad con el sentido de sistema significante. Afirmar que la lengua es un órgano de conocimiento implica también una concepción del lenguaje que se destrona con el siguiente verso del fracaso de todo poema, puesto que se lo que se conoce es el fracaso del poema al intentar nombrar lo inefable.

La no puntuación imprime al poema, además, una música particular, los versos, como se sabe, son unidades de sentido, en este caso, separados únicamente mediante la distribución tipográfica, que genera espacios verticales o silencios dotados también de significación. Por ejemplo, se realiza un juego paradójico entre la primera y la segunda estrofa: se acaba de afirmar que el silencio no existe y a la vez se plasma el silencio con el espacio entre las dos estrofas. Dicho juego es coherente con la estructura general del poema, pues posteriormente aparece un extraordinario silencio ante el cual se expresa una súplica: joh, quédate un poco más entre nosotros! Y, más adelante: ayúdame a escribir palabras. De manera que el yo del poema o autor ficticio se dirige en ocasiones a un tú particular que es el silencio, pero en general en el poema se realiza un soliloquio donde se expresa este yo que se desdobla:

\section{"mi persona está herida}

mi primera persona del singular.

escribo como quien con un cuchillo alzado en la

oscuridad"

La palabra yo no aparece jamás en el poema, aunque, como se sabe está tácitamente en muchos enunciados, pero quiero llamar la atención sobre el uso del uno inicial, que es una manera de nombrarse utilizada en el habla cotidiana que implica cierta generalidad, no es tan individual, implica a los otros; luego, en estos versos que cito, está presente el desdoblamiento: la persona es algo que le pertenece al autor ficticio, mas no es el mismo. Es decir: ella, que me pertenece (mi persona), está herida, así el yo se convierte repentinamente en un él, en referente y en el poema se quiere hacer consciente este procedimiento que se realiza en todo soliloquio donde se habla de sí mismo. Lo anterior se refuerza con el verso siguiente mi primera persona del singular, es decir, lo que conocemos como el pronombre yo. El uso de los conceptos propios de la gramática sugiere el juego paródico con un conocimiento lingüístico que ha privilegiado la forma significante.

Ese yo gramatical está herido, después de esta imagen hay un silencio y aparecen los siguientes versos que focalizan la contraparte: quien escribe atenta contra ese yo gramatical que mencioné, quien escribe es el sujeto agresor que ha herido a mi primera persona del singular. De esta manera se expresa en el poema el reconocimiento de un yo múltiple, dentro del cual también existen réplicas, en el sentido bajtiniano, pero también puede hablarse de una fragmentación del sujeto que imprime al texto relatividad ideológica y que se lía a un despojo del yo, en tanto éste último está condicionado por la cultura y por la lengua, de tal forma que el despojo del yo señala un no-ser en el cual se es. Este no-ser se conecta con el silencio, como veremos, pues indica la desnudez.

Lo anterior puede relacionarse, para mayor claridad, con la idea de crueldad expresada por Artaud, pues esta consiste en el esfuerzo por liberarse de la organización impuesta por la lengua y los demás sistemas de significación que estructuran la conciencia. Se requiere la crueldad entendida como el esfuerzo por destruir de todo aquello que hace parte de la organización, todo aquello que constituye el yo y que es ajeno al ser. Así, existe en apariencia una autoagresión en este poema, y en general en toda la obra de Pizarnik, pero interpreto aquí una acometida contra la mentira que constituye todo discurso, Alejandra Pizarnik, o el personaje que crea en el poema ( pues ambos terminan fundiéndose), no arremete contra sí misma porque sea una persona autodestructiva o decadente, simplemente sabe que ese sí misma no corresponde a lo que ES y ejerce entonces la crueldad con ese yo, se trata de la expresión del anhelo de desnudez que alcanza a deformar la organización.

Hay pues, una ruptura en relación con la organización tradicional del discurso poético, ya que se señala la posibilidad de generar sentido aun omitiendo los principales signos de puntuación. Este rasgo de ataque a las formas establecidas, aún dentro de la poesía, atraviesa toda la obra de Alejandra Pizarnik: en otros poemas utiliza la prosa, formas propias del teatro o una síntesis y fragmentación muy particulares.

Otro elemento que ha llamado mi atención en este nivel del discurso es la contradicción conciente que imprime una mayor ambigüedad al discurso y supone el reconocimiento de voces contrarias, aunque, según mi interpretación, en algunos casos se traen para destronarlas, como ocurre con el concepto de lengua antes mencionado.

En los últimos versos aparece de nuevo la paradoja:

“oh ayúdame a escribir el poema más prescindible

el que no sirva ni para

ser inservible

ayúdame a escribir palabras

en esta noche en este mundo" 
El poema más prescindible es aquel que no entra dentro del conjunto de aquellos objetos que sirven, así, lo más necesario es aquello que carece de uso práctico, se distingue lo prescindible o necesario para ser, de lo que "sirve", de lo que tiene un valor de uso. De igual manera se presenta como paradójico el anhelo del poema, pues se ha dicho anteriormente que todo poema está castrado por su propia lengua y es un fracaso. Esto indica, a la vez que hay una nueva significación para la palabra poema. Igual ocurre con las palabras a las que se refiere en esta última parte, tienen ya un sentido distinto al de las palabras iniciales, éstas señalan aquí las anheladas, las que no presentan escisión con lo que se quiere decir, a diferencia de las que hacen la ausencia.

De otro lado, además del soliloquio, el poema asume en momentos la forma de una oración, un ruego.

Inicialmente de afirma que:

Todo es posible salvo el poema

El silencio no existe

No obstante, quien habla, a pesar de haber negado la posibilidad de existencia de

estos elementos, convierte a uno en narratario anhelado (el silencio) - dios, a quien

se ruega, a quien se ora y al poema como la gracia que se pide a este dios.

En otra obra de Alejandra Pizarnik aparece el verso: la luz, no nombro más que la luz, quiero ver en vez de nombrar. Esta pequeña muestra sirve para señalar un elemento de la poética de esta argentina que resignifica algunas imágenes que componen en esta noche, en este mundo. Desde el título del poema se aprecia una constante alusión a la oscuridad que es una constante en toda la obra de Pizarnik. El yo del poema se halla en la oscuridad: la mente, el alma, el espíritu, las palabras anheladas no son visibles desde ese lugar oscuro que es el mundo, es posible que exista una alusión a la caverna platónica, pero en este caso, la luz emanaría del silencio, del no-ser en el cual se es.

El nivel del discurso se entiende como una forma compleja donde se encuentran varias voces, pues se considera que todo discurso es producción social en tanto no se encuentra nunca aislado, sino que está precedido por voces anteriores y va dirigido a alguien. Aunque el poeta no piense un lector específico ni esté condicionado por él, en el poema se prefigura un lector cuyos saberes comunes apoyen la comprensión e interpretación del texto.

En el caso de este poema se parte de algunos presupuestos que ya hemos mencionado: el reconocimiento de la escisión entre la representación y lo representado, el reconocimiento de una forma discursiva denominada poema y su tradición, el reconocimiento de la multiplicidad de voces que conforman al yo que escribe. Pero además, de manera más visible está implicada la alusión a dos obras de arte: La obra del pintor holandés Hieronymus Bosch o El Bosco (c. 1450-1516), denominada "La extracción de la piedra de la locura" que también corresponde al título de uno de los libros de Alejandra Pizarnik. En ella se alude de manera carnavalesca a la imposibilidad de extraer la idiotez de la cabeza de un personaje. En el poema, la piedra de la locura aparece en el oscuro escenario desde donde se pronuncia el discurso, la caverna laberinto prisión construida con el lenguaje, es en esta noche donde está oculta la piedra de la locura que no permite ver el silencio.

También se alude dos veces a Los Cantos de Maldoror, obra literaria del Conde Lautréamont, poeta francés de origen uruguayo precursor del surrealismo, igual que El Bosco en la pintura, pues su obra presenta un estilo alucinatorio y apocalíptico. André Bretón consideraba Los Cantos de Maldoror como "la expresión de una revelación total que parece exceder las posibilidades humanas".

Varios homenajes a la obra del Conde Lautréamont en los poemas de Alejandra Pizarnik señalan su admiración, y por tanto, su horizonte de maldoror con su perro, puede implicar el poema anhelado, la meta inalcanzable desde la caverna laberinto, pues teniendo en cuenta el esfuerzo que existe en el poema por romper las reglas gramaticales, expresado desde varios niveles discursivos, Los cantos de Maldoror que trastocan todas las reglas de la escritura poética y barren las certezas más antiguas, se erigen como modelo de ruptura y rebeldía incluso con las formas poéticas.

A través de los diversos juegos con el lenguaje de los cuales hablé en el nivel de la enunciación, se señala también la relación yo - tú, pero adicionalmente existe una paradoja que engloba el texto: En un poema se ruega al silencio para que ayude al poeta a escribir un poema. De manera que lo que leemos no es, para quien se expresa en el texto, un poema y el poema mismo deja esta incertidumbre en el lector.

La constante fragmentación, el juego con las voces y la falta de puntuación en el nivel de la enunciación y los presupuestos que acabamos de expresar, implican un lector dispuesto a jugar y a permitirse el horror, pues indirectamente, la autoagresión, o mejor, la crueldad presente en el poema, se vierte en el lector a través del juego especular.

Por último, quiero expresar mi acercamiento a la expresión de la construcción de sentido del silencio estético inherente al caso Pizarnik: Existen muchas maneras de entender el silencio, ya sea dentro de la cadena de significantes, como una pausa en la partitura del texto, o como correlativamente funcional respecto al texto entendido como totalidad. Retomo en esta parte, algunos elementos del trabajo anterior que son necesarios para la comprensión del texto (silencio estético) que me he propuesto analizar y su relación con el poema en esta noche, en este mundo.

El silencio en tanto cuerpo intangible de la enunciación, implica una posición ética en relación con el lenguaje, que se sostiene en la pregunta por la conexión entre la representación y lo representado. Echevarría, trazando un recorrido por distintas 
concepciones del lenguaje, habla de una mirada premoderna, antes de la escritura donde ubica el lenguaje del devenir donde lenguaje y acción estaban entonces estrechamente unidos. ${ }^{5}$ En el poema de Alejandra Pizarnik, según interpreto, hay una alusión a la escisión entre lenguaje y acción en los versos:

"si digo pan ¿comeré?

Si digo agua ¿beberé?

El pan y el agua son necesidades mínimas que pueden asociarse con la idea de estar preso; la enunciación no implica la acción. Esta duda se conecta con el pensamiento que expresa Echevarría en su texto y como lo mencioné anteriormente, con una tradición crítica del lenguaje.

Partiendo de la concepción del lenguaje anterior, interpreto el silencio como un acto voluntario precedido de una experiencia con el lenguaje que ha llegado a un límite. De tal manera que el silencio aparece como un desbordamiento del ser que no soporta las barreras del lenguaje.

Nietszche y Artaud coinciden en la búsqueda de la antimímesis o destrucción de la idea de que el lenguaje sirve para representar el mundo, para lo cual el filósofo crea el concepto de voluntad de poder y el artista, el concepto de crueldad. Ambos ven el arte como la posibilidad de acercarse a la total desnudez del ser y sin embargo, al final optan por el silencio. Así se entiende lo inefable, desde esta perspectiva, como aquello que está fuera de las cercas del lenguaje constituidas por un reciclaje de ideologías, conocimientos y rituales o lugares comunes.

Si el yo no puede existir sino como un recipiente lleno por las voces que la sociedad y la cultura han depositado en él, Nietzsche y Artaud indican caminos que implican el vaciamiento de ese recipiente, a través de la supresión de la representación y la creación de un nuevo lenguaje que borre todo límite creado por la lógica de la razón. Así, la experiencia peligrosa del silencio, anula al ser en el campo social, y a la vez muestra la amplitud y complejidad del ser humano, que se olvida en ocasiones, en el campo de la lingüística, absolutamente restringido a la lógica corriente y aceptada por la sociedad.

Maurice Blanchot, afirma que realmente el silencio existe: "no es ni la muerte, ni la palabra", existe algo que no es ni la indiferencia ni el discurso, y ese algo, no transmisible por el lenguaje, es suficiente para sembrar la duda acerca de su capacidad de cumplir correctamente su misión. Es posible que las palabras desconozcan la verdadera naturaleza humana, ya que ciertos momentos de la vida humana o experiencias posiblemente esenciales como el éxtasis y el sueño, tienen una correspondencia más justa en el silencio que en el discurso.

5 Echevarría, Rafael. Ontología del Lenguaje. Santiago, 1996. P. 20

6 Blanchot, Maurice. Falsos Pasos.Editorial Pre-textos. Valencia, 1977. P.101
De esta manera, se muestra un acercamiento a la experiencia inefable a través del sueño, el grito, el éxtasis, tal vez también la risa y el llanto, es decir, toda experiencia emocional que saque al ser de la normatividad y del ritual. Sólo que como se ha dicho, la sociedad controla los seres humanos, impidiendo la salida de las reglas o bien marginando a quien no actue según el deber ser que ella impone.

Para Gastón Bachelard, la ensoñación es también un desplazamiento del yo, un instante en el que el ser vive el no-yo. Así, deja que Víctor Hugo nos hable de lo inefable: Todo esto no era ni una ciudad, ni una iglesia, ni un río, ni color, ni luz, ni sombra, era la ensoñación. Permanecí mucho rato inmóvil, dejándome penetrar dulcemente por este conjunto inexpresable, por la serenidad del cielo, por la melancolía de la hora. No sé lo que pasaba en mi espíritu, y no podía decirlo, era uno de esos momentos inefables en que uno siente en sí algo que se adormece y algo que se despierta.

Este adormecerse, podría entenderse como la muerte del yo, y el despertar, como la entrada en otra lógica. Bachelard afirma que la ensoñación no se cuenta, es imposible de decir verbalmente, sólo se escribe a través de la literatura, más específicamente de la poesía.

Partiendo de lo anterior, se entiende que para nombrar los nuevos modos de experimentar el mundo y a sí mismo, se requiere fundar un nuevo lenguaje, aventura en la que el ser, socialmente, está condenado a desaparecer. En el caso de Alejandra Pizarnik, el anhelo de silencio devino suicidio, pues no halló salida en el mundo para expresar con sinceridad absoluta o con precisión, lo inefable. Pero lo que me interesa aquí es el suicidio como acto estético que señala una coherencia total entre palabra y acto. En toda la obra se expresa su necesidad de DECIR y se señala la imposibilidad, dicha angustia hacía de Alejandra (el personaje de sus poemas) un ser que no tenía otra alternativa que la muerte para encontrar el silencio, aunque allí no fuera escuchada. Pero el personaje, como es frecuente en varios surrealistas, se funde con la persona, con la poeta, permitiendo la reunión de palabra y acto. La voz se silencia, pero paradójicamente, este silencio está lleno de sentido. El silencio se vuelve contra el lenguaje extrayendo a la vez, tal vez, su verdadera esencia.

Teniendo en cuenta las necesidades, las intenciones y el agente que produce el silencio se le puede caracterizar como anhelo de verdad. Se trata de un silencio voluntario, pensado, que apunta a traspasar los límites del lenguaje corriente. Este sería el común denominador para autores como Antonin Artaud, Andrés Caicedo, Alejandra Pizarnik, Artur Rimbaud, entre otros, quienes, en algunos casos, tematizaron la problemática del lenguaje y dejaron como última forma de enunciación el silencio. En estos casos, el silencio se hace significativo al oponerse a una tradición de continua producción

7 Bachelard, G. Poética de la Ensoñación. Fondo de Cultura Económica. México, 1993. p. 27 
artística y se erige como un texto sin cadena significante alguna, que acompaña la obra literaria.

\section{REFERENCIAS BIBLIOGRÁFICAS}

Bachelard, G., Poética de la Ensoñación, Fondo de Cultura Económica. México, 1993.

Blanchot, M., Falsos Pasos, Editorial Pre-textos. Valencia, 1977.

Doumille, Nietszche y Artaud: por una ética de la crueldad, Siglo XXI Editores, París, 1992.

Echevarría, R., Ontología del Lenguaje, Santiago, 1996.

Nietzsche, F., Sobre la verdad y la mentira en sentido extramoral, Tecnos, Madrid, 1990.

Pabón, C. “Estética de la crueldad - América cruel”, Texto y Contexto, № 22, octubre/diciembre 1993, $74 / 97$.

Pizarnik, A., Obras escogidas, Ediciones Hölderlin, Medellín, 1996.

Ramírez, L. A., "Verdad y Subjetividad en el Discurso", en Lenguaje y Cognición, Universidad de Salamanca e Instituto Caro y Cuervo. Bogotá, 2002.

----, La Violencia con el Lenguaje, Fotocopias suministradas por la cátedra.

Rella, F., El Silencio y Las Palabra, Paidós, Buenos Aires, 1981.

Tobón Franco, R., Semiótica del Silencio, Editor: Fernando Salazar. Concejo de Medellín, 1987. 